\title{
A short enquiry into the origins and uses of the term "neogeography".
}

Draft

Let me first state at the outset that I am not a lexicographer or etymologist, a GIS specialist, or even very much of a practical neogeographer. This paper was written in a weekend, simply out of intellectual curiosity and the need to prepare for a PhD application interview. So please forgive any errors that I might make here.

\section{2 to 1960 s. Early usage:}

The earliest known usage of the term neogeography dates from 1922, when the Yearbook of the Carnegie Institution of Washington contained the following comment...

"Palaeogeography has a far wider field and can only be defined in the terms of neogeography".

Here the term clearly appears to suggest: a new, emerging and not yet fixed field within academic geography as it then existed. It is used to refer to the newly emerging study of the ancient geology of the Earth's surface.

The Encyclopaedia of Bible Life (1944), states...

"between the extremes of the geopoliticians and the non-environmentalists, the neogeographers have adopted an intermediate position in which the effect of geography can be plainly traced in some instances in human conduct". (Miller \& Miller, 1944)

This later instance suggests the existence of some definite tendency called neogeography. The usage clearly links geography to the study of human activity.

A paper in the scholarly publication Chronica botanica: an international biological and agricultural series (1950-54) used the term in concluding that...

"Neogeographers seem to avoid consultation with well-informed and easily-available specialists in other fields". (v.14, 1950-54, p.182)

It is curious that this use appears in the field of biology and agriculture, since the previous examples occurred in the field of palaeogeography. Was this terse comment perhaps a criticism of Soviet 'science' as practiced under the leadership of the charlatan biologist Trofim Lysenko? In this respect it is interesting that the term also occurs a little later in the title of a 1950s(?) citation given in Soviet Geography: review and translation (1960, American Geographical Society of New York). The Russian article that Soviet Geography cited was by K.K. Markov, and was titled in translation as "Historical Earth Science - Transformative Earth Science: from Palaeogeography to Neogeography". Nothing can be concluded without further study, however. I happily leave that task to the professional lexicographers and etymologists. 
The term neogeography also occurs in the U.S. scholarly journal Sociological Abstracts (1952), in which one of the abstracts talks of... "the neogeography of production \& work", neogeography being one of the named themes around which three symposia in sociology had then been organised. It is difficult to determine if this 1952 instance, like that of the 1922 instance, and possibly the 1944 instance, might simply be using neogeography to mean: an emerging or not yet fixed field of study. If so, then neogeography may have been a conveniently vague umbrella term for what would eventually be a multitude of named frameworks and focussed areas of study.

\section{Francois Dagognet:}

The French philosopher Francois Dagognet used the word in the title of his Une Epistemologie de I'space concret: Neo-geographie (1977). DeJean (1997), translating part of what seems to be Dagognet's as-yet-untranslated book, states that he defined a neo-geographic practice as being psychological in nature...

"a relational field [of] irradiations, numerous fragile paths, proximities and distances, an ensemble that can be said to constitute a personality" (DeJean, 1977, p.91 - translation of p.174 of Dagognet).

A "field of irradiations" and "fragile paths" that combine in what is presumably a very personal psychological "ensemble".... some readers may see here a similarity to the Lettrist /early Situationist practice of derive as part of psychogeography. Yet that would be a misleading assumption. It seems more likely that Dagognet's idea of neo-geography was operating within the wake of Henri Lefebvre's influential book La production de l'espace (1974) - although even there we might find a northwest passage back to the early Situationists, since Lefebvre's Critique de la vie quotidienne (1947) is said to have inspired COBRA, and Lefebvre knew some French Situationists between 1957 1961 (relations were strained) and he was aware of experiments with derive and unitary urbanism. Yet Lefebvre has stated: "My thinking about the city had completely different sources" (Ross, 1983).

Lefebvre's La production de l'espace had suggested a useful distinction between our actual perception of a material concrete space (a perception, or set of perceptions, which Lefebvre implies cannot be measured), and our abstract mental conception of that same space...

"Concrete space is the space of gestures and journeys, of the body and memory, of symbols and sense. This concrete content, of time inscribed in a space, is misunderstood by reflexive thought [i.e.: by the thought of architects \& planners], which instead resorts to the abstract space of vision, of geometry. 'Abstract space [ "the space of technology, applied sciences, knowledge bound to power"] is measurable' [writes Lefebvre] " (Elden, 2004, p.189).

Taking both the translation of Dagognet and Elden's interpretation of Lefebvre at face value, there would thus appear to be some possible linkages between the "Neo-geographie" of Dagognet and the contemporary definitions of neogeography which my paper seeks to explore. It seems to me that some contemporary neogeographers seek to prototype new tools in order to capture, describe and record Dagognet's "field of irradiations" and "fragile paths", and that they do this to explore the psychology of place. Let me rephrase that, in a slightly clearer language - they seek to capture, describe and record the tacit unspoken nature of immediate lived experience in a particular space. 
I am thinking here of specific early prototype neogeographic tools such as the GSR finger-cuffs and GPS used by London-based researcher-artist Christian Nold and others to create the Greenwich Emotion Map (London, October 2005 to March 2006), a map which was then placed online as part of the Google Earth layer sets. (Nold, 2005). Nold's project attempted to record fleeting impressions, memories, and arousal states, and sought to map these to exact locations in urban London.

\section{Kenneth Dowling:}

Nicholson Baker, writing in the book "Reclaiming San Francisco: history, politics, culture" (1998), specifically attributes the coining of the word neogeography to Kenneth Dowling, then the Librarian of the City and County of San Francisco, who is reported by Baker as using the term to describe the study of a new field of social relations...

"what he has called the 'neogeography' that is created by virtual communities formed of individuals who are far away from each other physically". (Brook, et al, p.37)

It is just possible that Dowling may have remembered the use of the word among U.S. sociologists of the early 1950s, and then wished to apply it to the study of new online communities. Yet that is merely my speculation. There are no locatable publications by Kenneth Dowling which use or define such a term. Nor is there any description of Dowling's possible tools or methods.

\section{The use of the term in the $20^{\text {th }}$ century:}

It seems clear from the above examples that the term neogeography had been used in the $20^{\text {th }}$ century to refer to: i) an emerging academic approach to certain new aspects of geography, perhaps those taking in "a wider field" than was currently accepted; ii) a new academic approach that may have been somewhat irregular, and perhaps concerned with tenuous and difficult-to-capture aspects of geography; iii) that, at least since the mid 1940s, the term may have been used to refer to the study of the complex interrelationships between people and geography, possibly in a historical or even a biological framework; and that iv) that at some time shortly before 1998 the word was being proposed informally by some scholars in the U.S. to describe the possibility of serious study of the new online communities and discussion groups.

\section{March 2005. The geoaware/geospatial Web:}

On $4^{\text {th }}$ March 2005, Jon Udell influentially summarised his ideas about the potential that lay within the new infrastructure of mobile collaborative map making and usage, in an article in InfoWorld (a publication for I.T. professionals) titled: "Annotating the planet with Google Maps".

In the article, written for a professional audience, Udell referred to Google Maps as a key tool for enabling "the geospatial Web" and "the geoaware Web". Such terms can of course be dated back to ideas put forward in 1994 in the technical concept paper by Charles Herring titled "An Architecture of Cyberspace: Spatialization of the Internet". From around the early-mid 1990s, internet 
buzzwords with the "geo"- prefix had become relatively common in the trade press, as did "augmented reality", spinning off from the over-used term "virtual reality". The similar term "locative media" seems to have emerged around the year 2002, from the pen of the new media theorist Lev Manovich. All of the above terms are specialist terms, unlikely candidates for wider popularisation across disciplines or to be used to convey ideas to an informed public.

Yet Udell's 2005 InfoWorld article was about neogeography in all but name. He refers to new unofficial uses of the just-launched Google Maps service. Uses that - just over a year later - would easily be described using the term neogeography...

"Craig Thrall sent me the bombshell that blew up my schedule for the next 24 hours. "A friend of mine figured out how to download Google directions into his GPS," Craig wrote, "and also use the Google Maps front end to display his GPS." The friend is Matt King, and his proof of concept is a JavaScript bookmarklet that uses Google Maps to display a walking tour of Beverly Hills, with waypoints labeled and linked to photos. I picked up [purchased] a Garmin Geko 101 and went for a walk. When I finished making the interactive version of my neighbourhood tour, along with a screencast, it was clear that Google Maps is every bit as revolutionary as my first instincts told me. Not because Google invented a new geospatial engine or compiled better data. They didn't. But simply - and yet profoundly - because Google Maps is a framework we can all use to annotate the physical world. In the very near future, billions of people will be roaming the planet with GPS devices. Clouds of network connectivity are forming over our major cities and will inevitably coalesce. The geoaware Web isn't a product we buy; it's an environment we colonize. [...] Radical openness is the key. It's been only two weeks since it launched and already the colonization has begun." (Udell, 2005)

Although the term neogeography was not used by Udell's article, it is clear that what he is describing here is first a mashup, and then a form of personalised ad-hoc map-making (a Garmin Geko 101 was an entry-level GPS receiver), both of which have implied social value. When judged against the definition of neogeography that was to be published just over one year later, Udell was clearly outlining two key areas of contemporary neogeographic activity.

\section{June 2005. Where 2.0:}

On $29^{\text {th }}-30^{\text {th }}$ June 2005, in San Francisco, the publisher O'Reilly held his first “Where 2.0" conference. In the keynote speech at the conference Tim O'Reilly stated that...

"Where 2.0 is the subsystem to the Web 2.0 operating system [...] Web 2.0 will be built from a network of cooperating data services. [...] ESRI, MapQuest, and Microsoft MapPoint offered Web services APIs with lots of usage ... but they are not hacker friendly [...] "Google maps with Craigslist is the first true Web 2.0 application, neither of the sites [owners] was involved [...] a developer put it together [...] Hackers are teaching the industry what to do." (Jablonski, 2005).

Whereas Udell's March 2005 article had used the existing but clunky labels such as "the geospatial Web" and "the geoaware Web", in June 2005 Tim O'Reilly tried to coin a catchier and more press- 
friendly term. The "Where 2.0" label was intended to describe the technical foundations for the practice of what is now so often known as neogeography. The O'Reilly Where 2.0 conference series continues, annually, but the term Where 2.0 does not seem to have gained any real acceptance or use other than as an O'Reilly brand name.

\section{March 2006. The book Else/Where:}

In March 2006, the sought-after book Else/Where: Mapping - New Cartographies of Networks and Territories was published. The book was an advocate for new approaches to mapping to be considered as an intrinsic part of contemporary design practice (no contributors to the book were professional cartographers). The book...

"charts the ascendancy of mapping as a powerful interdisciplinary strategy that links people and places, data and organizations, and physical and virtual environments. Featuring 40 essays by writers from the U.S. and Europe and several commissioned projects." (publisher publicity for Abrams and Hall, 2006)

The word neogeography is not used in the book. Instead the book's weightier contributors use such terms as: "network mapping" (Dirk Van Weelden); "a dissident cartographic aesthetic" (Brian Holmes); and "mapping and counter-mapping" (J.J. King).

\section{April 2006. Randall Szott defines neogeography:}

The academic/arts weblog Placekraft [ placekraft.blogspot.com ] was written by an apparent 'collective' by the name of 'Dilettante Ventures'. This collective is actually just one person, Randall Szott. On $7^{\text {th }}$ April 2006 Szott noted on his weblog, in his short posting titled "Psychogeography vs. Neogeography"...

"We have to credit the people at Platial for coining (we believe, or at least popularizing) the term neogeography. It's a much needed term to replace the often overused psychogeography. The term is sufficiently abstract to serve as a broad category of un/nonprofessional geographic practices (walking mapping, [geo-spatial] tagging, etc.)." (Szott, 2006a)

On $26^{\text {th }}$ April 2006 Szott stated, on the same weblog, that in his view current neogeography can be defined as...

"a diverse set of practices that (mostly) fall outside the professional geographic domain. Rather than making claims on scientific standards, methodologies of neogeography tend towards the intuitive, expressive, personal, absurd, and or artistic, but may just be idiosyncratic applications of "real" geographic techniques. This is not to say that these practices are of no use to the cartographic/geographic sciences, but that they usually don't conform to the protocols of professional practice. 
Neogeography is, or should be, broad enough to include, urban exploration and its Situationist offspring (like psychogeography), illegal architecture, site-specific sculpture, collaborative mapping, geo-tagging, guided walks, ephemeral cities (Burning Man [the event] for instance), imaginary urban planning (see Urville), altered maps, travel writing, place based photo blogging, etc.

When one asks what connects all of these activities, there may not be a clear answer, but they all fall, however tangentially, in the realm of geography (usually "humanist"). Neogeography, to rework Elizabeth Grosz, is an attempt to explore geography "from the outside." (Szott, 2006b)

On May $27^{\text {th }}$ 2006, Szott, as Placekraft, posted on the Platial News: The official weblog of Platial his further elaboration of neogeography, titled "What is neogeography anyway?" (Szott, 2006c). This was essentially a reiteration of the $26^{\text {th }}$ April 2006 posting on his personal weblog.

The website and active neogeography discussion forum www.neogeography .net appears to accept, at July 2008, that neogeography now broadly covers the following activities...

"geo-tagging | guided walks | ephemeral cities | imaginary urbanism | altered maps/radical cartography | travel writing | psychogeography | place-based photo blogging | urban exploration | site specific sculpture | land/earth art".

The neogeography .net domain name was registered by Jeffrey Barke on $25^{\text {th }}$ July 2006. Comparison of the above categories with Randall Szott's definition clearly shows that the website neogeography .net are the same as those given in from Placekraft's text of $26^{\text {th }}$ April 2006.

\section{April 2006. Report of coinage by Di-Ann Eisnor:}

The first contemporary usage of neogeography is attributed by the unreliable Wikipedia to the coowner of the online maps mashup website Platial [www.platial.com ], Di-Ann Eisnor.

This Wikipedia claim probably rests on the fact that Eisnor was credited with the coinage by a journalist, in a print article dated $25^{\text {th }}$ April 2006. The term neogeography seems to have first appeared in the contemporary press in a short journalistic article by Joab Jackson for National Geographic News, titled: "'Neogeography' Blends Blogs with Online Maps". Jackson's article states that it was...

"Platial co-creator Di-Ann Eisnor, who coined the term "neogeography," (Jackson, 2006)

...but his article gives no example of the term's usage by Eisnor.

Randall Szott's first weblog posting (Szott, 2006a) about the term seems to concur that the origin lies with Platial. It is possibly that the word appeared in the title of the Platial weblog, which seems to have begun in Spring 2006 and was called Platial News and Neogeography. There appears to be no other documentation available as to when or how it might have been first used by Platial Inc. or its owners, either on the Platial website or to be found by searching online. 
When Eisnor was interviewed for the weblog Mike's Corner (interview posted online $11^{\text {th }}$ July 2006), rather than pointing /hyperlinking to her own first usage and its context and meaning at that time, Eisnor responded...

Question: Could you explain neogeography in layman's terms?

Answer: I found this definition on the Placekraft site. [ Eisnor then proceeds to give parts of Randall Szott's text ]

(Price, 2006)

This is the earliest instance that can be found online in which Eisnor publically uses, refers to, or responds to, the word neogeography.

It is possible that the term was indeed originated by Eisnor and Platial, although in informal use, such as in private discussions by email, or verbally at conferences, and that it then found its way into the title of their weblog Platial News and Neogeography. T he earliest existing online reference to a weblog of that precise name is a Ma.gnolia bookmark page dated $15^{\text {th }}$ March 2006.

No other mention of, or attempt to make a definition of, the word neogeography appears to have been made at Platial's weblog, until the 'Placekraft' posting there by Randall Szott on May $27^{\text {th }} 2006$.

\section{June 2006. Popularisation of the term:}

A Wired News item of $16^{\text {th }}$ June 2006, "Where 2.0 Gives the World Meaning", reported on the O'Reilly conference Where 2.0, where the journalist says of the activities of young Christopher Schmidt and his GSMLOC mapping project...

"Calling himself a "neogeographer," Schmidt is part of a generation of coders whose work is inspired by easily obtained map data, as well as the mashups made possible by Google Maps and Microsoft's Virtual Earth."

In December 2006 the publisher O'Reilly produced a pamphlet by Andrew Turner, as part of their popular 'Short Cuts' technology series. It was titled Introduction to Neogeography (2006) and appears to be the first English-language publication to use the term in the title. Turner defined the term neogeography to describe an emerging field in which...

"complex techniques of cartography and GIS [are] within reach of users and developers" ... [due to] "a growing number of tools, frameworks, and resources available that make it easy to create maps and share the locations of your interests and history" [...] "Essentially, Neogeography is about people using and creating their own maps, on their own terms and by combining elements of an existing toolset". (Turner, 2006)

There seems one obvious difference from Szott's wider definition of neogeography. The named activities which Szott hopes will "explore geography "from the outside"." are not included by Turner. Rather, Turner seems to invite non GIS-industry "users and developers" to explore geography from the inside, using "existing toolset" $(s)$. 


\section{December 2007. “Neogeography - towards a definition":}

A year after the publication of his book Introduction to Neogeography, on $6^{\text {th }}$ December 2007 Andrew Turner posted on his personal weblog that...

"Over the past day there has been a large discussion about "what is neogeography" in the geoblogosphere. [...] It's apparent that, given the quick and large-scale response to the original impetus, that this question has been brewing in the minds of many geo-types." (Turner, 2007)

Turner's weblog posting was titled "Neogeography - towards a definition". In it he pointed out that neogeographers were at that time not only or simply mashing up free online services without adding content or a level of analysis. He noted a feedback loop in some instances, whereby...

"GIS experts are then utilizing these [neogeography] data and tools for analysis, coordination, and decision support".

He then goes on to concisely and dryly define neogeography as being...

"geographical techniques and tools used for personal activities or for utilization by a nonexpert group of users; not formal or analytical"

The public comments made at the foot of his weblog posting suggest alternative terms such as "Geography 2.0", "Amateur Geography", and "NeoGeo" (this last for speed of online typing?). These potential alternatives suggest that the word neogeography, at least in some areas of the commercial GIS industry, had then not yet achieved a real acceptance. I have also heard, elsewhere, the term "Participatory Urbanism" used by architects to cover aspects of neogeography. It may be that architects, so far virtually silent in the debate, will also suggest new terms when they arrive.

One commenter on Turner's weblog posting noted, however, that the GIS World magazine (Dec 2007) had asked the question: "Does neogeography help or hurt the geospatial industry?" as part of the annual "Industry Outlook" feature. This suggests the term had by then become commonly understood within the commercial GIS industry.

\section{Late 2007, early 2008:}

Turner's 2007 weblog posting appears to assume that its audience lay in the tight world of both the GIS specialists and the dedicated and highly-informed amateur neocartographers (a more precise name, by which I would distinguish them from the wider practices of neogeography) who had by then emerged. These are two intelligent groups who will surely eventually learn from, overlap, and eventually intermingle with each other - even if only in order to keep pace with demand for new products in the face of the rolling combination of: cheap sensors; the growing level of processing power; more sophisticated web browsers and faster broadband; and innovative applied mathematics. One must also take account of the unavoidable demographics of the coming "talent crisis" and the retirement of the 'baby boomers', as a spur toward integration of these two groups. 
Such an inevitable overlap and intermingling may also serve to address present-day problems in neogeography such as: i) the quality of data sets / real-time feeds; ii) managing the growing complexity of mapping mashups; iii) the general 'beta' nature of neocartography products; iv) the lack of trust in 'crowdsourced' data; and v) the inability to extract profit from many neogeographic products. Intermingling would also help to evolve neogeography products towards being far more than a simple digital recreation of 'tracing-paper overlays / push-pins in maps', and move them toward being sophisticated spatial services that operate as real-time feedback loops using real-time data feeds. Such a move to more sophisticated and robust products would, of course, entail dealing with city-wide issues of planning, funding, maintenance, power-supply, security, redundancy, and interoperability - all issues that would seem to require far more than a casual approach.

\section{The politics of deployment:}

Both the GIS industry and the neogeographers might contribute toward developing a firm stance on the ethics of the intrinsically-political uses to which such products can be put. We must hope that our new techniques and capabilities will be used wisely, for social governance and the greater good. However, they could easily be used for the purpose of repression and the restriction of our liberties. This latter point will be particularly important if our new techniques start to become 'socially invisible', taken for granted, and generally not considered to be topics for political or ethical enquiry (except by cranks and ranters) - a historical example of such a technical/cultural process might be the historic deployment of CCTV in the UK.

Such a critical stance could be especially valuable if our new techniques start to be very widely and expensively deployed, but in some cases have little practical value and many disadvantages on the ground - this seems to be what has happened with CCTV in UK, as found by several substantial studies of CCTV (such as Gill and Spriggs, 2005). One outrider of such a failure may be a recent study from Japan which talked of the "ineffectiveness" of GPS for urban walking ...

"GPS users traveled longer distances and made more stops during the walk than map users and direct-experience participants. Also, GPS users traveled more slowly, made larger direction errors, drew sketch maps with poorer topological accuracy, and rated wayfinding tasks as more difficult than direct-experience participants." (Ishikawaa, 2008)

Society might avoid much cost and effort, if a few informed voices were to speak up at the start of the deployment process of what may be an ineffective technology. We might thus avoid follow-on effects where the mass deployment of a new set of surveillance technologies cascade down into the making and shaping of new urban spaces, the perverting and re-shaping of law, and eventually even influences the private thoughts of citizens in the spaces thus re-shaped. Such a critical stance might be all the more important because, unlike CCTV, our new 'neogeographic' technologies have the potential to be both invisible but also truly ubiquitous.

There is thus a distinct risk in casually allowing the definition of neogeography to narrow to mean instead 'neocartography', and then to fade from view over the years. Keeping the definition of neogeography wide enough to include experimental and artistic practices that come 'from the outside' seems to me to contain a vital practical element of a meaningful and full neogeography. 
Some may baulk at the prospect of a discipline that has to negotiate and triangulate between technologists, amateurs and artists. But how else might we enhance (or keep hidden) some of the mysteries of place, in this potentially invasive new world we are starting to build? In his examination of PrairyErth, Christopher Gregory-Guider usefully points out that it is possible for suitably flexible minds to consider a space both 'from the outside' and 'from the inside', when he talks of...

"the way in which [ William ] Heat-Moon combines [ in the book PrairyErth ]highly structured, mathematically precise cartographic exercises with more subjective and discursive mapping methods" (Gregory-Guider, 2007)

\section{Toward a wide definition of neogeography:}

It is clear that Szott's definition of neogeography is wider and more inclusive than Turner's, and is one that suggests that there are other groups who must be considered. In the above section I have laid out my speculations about why we might need to widen Turner's definition of neogeography, which is,...

"geographical techniques and tools used for personal activities or for utilization by a nonexpert group of users; not formal or analytical"

... to encompass the wider artistic/creative responses and groups involved in neogeography, such as those identified above by Szott's (2006b) definition.

Szott's definition lists artistic/'outsider' neogeographic activities that I would view as, in close comparison with Turner:- i) often having approaches or components that are "formal or analytical" after their own manner; ii) often going beyond or avoiding standardised "techniques and tools"; iii) usually balancing a wider social engagement with an approach focussed purely on "personal activities", and iv) involving a wider social engagement that will reach local people who are, in effect, an "expert group of users" in their particular locality and their regular travel routes.

I hope that neogeography - yes, let us call it that, after all - will become a coherent and widely accepted term, but that the term neocartography will perhaps define the technical subset of it. And I hope that neogeography becomes a deeply inter-disciplinary and holistic practice. Neogeography should describe not only specific tools and associated narrow services and techniques (neocartography?), but also many elements of a new and seemingly popular global engagement with location, maps, mapping and the visualisation of large-scale datasets.

In other words, neogeography should attempt to avoid the 'forking' that seems to have already happened in locative media: a forking between hardware-oriented consumer-facing services (work tools) and artist-initiated wide-gaming (such as ARGs) and art-practices (play tools), each now administered by separate urban tribes.

Expanding on the "from the outside" neogeographic activities listed by Szott, in my conclusion I will now outline some of the 'fringe' and 'playful' activities that I would add to the list. I also attempt to herd these into one of four categories. 


\section{Conclusion:}

Following Szott's definitions, and taking my lead from Henri Lefebvre's previously discussed split between perception and conception (as you will recall, those made in his book La production de l'espace, 1974) I suggest that the use of the term neogeography should be understood as also embracing one of the following four areas:-

1) 'Perception' of place:

Activities that seek to uncover, to map, to measure, pin down, or place what has been previously thought to be unmappable or unplaceable or unmeasurable.

These might include: - emotion mapping (Nold, 2005); personal memory-mapping during travel; fleeting 'ambience conveying' combinations of smells, heat, taste, touch, noise, and then potentially the deliberate choreography of these; preservation of extinct or endangered sounds, at their location of occurrence; mapping of aggregate moods (such as stress levels, happiness, even cultural tastes), derived from the anonymous sampling of tone-of-voice data from mobile phones or interactive clothing; stance and gesture-mapping, through analysis of CCTV footage; location-based 'experience archives'; examinations of thresholds and boundary areas; documentation of encounters with fleeting natural elements such as weather events, watercourses, and animals; general tracking of things previously assumed not to be amenable to tracking.

\section{2) 'Conception' of place:}

Structured activities that work within the actual realm of the planned, the measured and the built environment, and which may use actual objects with a place. These will often, but not always, be intended to be new forms of communicative media.

It might just be possible to broadly divided these into tactile 'objects' and invisible 'traces'.

These could include:- meaningful place-related interactive and data/sensor-driven art, including non-decorative projected-light and stereo-3D sculptures (trace via object); personification of places as projected avatar-characters; digitally annotated spaces (trace); mobile collaborative mapping systems (trace via object); cheap printable RFID stickers that communicate with phones (trace via object); real-time information feedback loops - data collection from mobile phones - transfer, aggregation processing and mapping - and then back to display on the phones again, and so on (object-trace-object-trace); performance-art interventions in official urban space (object); pranks and spoofing of 'intelligent' urban spaces that appear to have an anticipatory intelligence that can be played with; extreme or irregular or nomadic building (object); per-visitor customisable signage (object); customisable place elements (object); geo-caching (object); location-based mobilecoordinated games (mostly object); soundshaping and place-calming (systematically identifying and reducing noise, light, vehicle access, clutter levels, litter and graffiti) as part of place-remaking; some radical forms of genuine community planning.

3) Writerly and/or storytelling practices:

These might include: - Contemporary psychogeography (which is more than an early and failed Situationist practice - as Coverley shows) and imaginative forms of documented urban exploration; 
walking as an art practice (Certeau, 1980, and many practitioners such as Long and Fulton); remotely/digitally annotated or tagged spaces; writing practices around place-based wikis, blogs, travel diaries, photo-sets, data-sets; storytelling with maps, data and places, to capture elements of complex social processes; maps-as-communities; life-blogging (e.g.: auto-generated printed "personal annual report" that sum up a year's travels and locations, drawn from your personal data sets); storytelling with/through maps and data; art maps, fictional maps; deep maps (GregoryGuider, 2007); the mapping of mental landscapes; locating items from local newspaper archives and oral history (perhaps with place-names automatically tagged so they can be speedily referenced to places); satnav-delivered/place-triggered storytelling and local histories (Shanahan); locationsensitive podcasts; having geographically-located objects blog (i.e. an ancient tree wired with cameras, sensors and wi-fi, can be made 'to blog'); certain forms of object-collecting practice, if the parts of the collection are referenced back to the place they were found.

4) Remote social-mapping media:

These are the usual and much talked-about range of neogeographic activities, such as public online annotation and tagging of maps or other place-based representations. However, even within these activities there may be creative engagements.

These might include:- Artists working with maps and data visualisation; the collaborative use of the map-based level-editors that come with many videogames, in order to make new virtual game spaces; using real-time remote data feeds to drive generative screen-based artworks; remote curation of events, or caretaking of places; virtual tourism (possibly even with mobile telepresence via robots); auto creation of 3D models of landscapes, buildings, purely from a set of online photographs; general usage of online mapping services in unusual or unexpected ways; usage of mapping in ways that are officially disapproved of or illegal (e.g.: crime+racial profiling at street level).

All of the above activities, from any of these four categories, may have unexpected uses - especially in unexpected recombination with each other, or in unexpected combination with yet-to-beinvented technologies or with old failed technologies. There will also be many forms of visualisation (mapping) of data that do not originate from the measurement of real places, but comes rather from things like automated analysis of texts or speech. One such example would be the website wefeelfine.org. There is, however, nothing to stop such visualised/mapped data flows from finding their way into actual places.

\section{A final caution (1). On the 'politics' of artists:}

Before we are swept away with all things digital and interactive, to the Gleaming New Land of Interactivity, it is useful to consider that the possibility that so-called "radical" art activities in neogeography may be more "rebel sell" (Heath and Potter) than "rebel yell", despite the art being so often wrapped in stale third-hand claims about political and cultural agency. From the perspective of the art historian of 2030, neogeographic artists may be been seen as having done the (dirt cheap) $R \& D$ for those who later went on to develop compelling money-making neogeographic media and applications. It would be pleasing to think that the artists and the money-makers in that instance 
could be one and the same, but this seems unlikely. Good artists are intensely entrepreneurial in their skills sets and flexible practices, but all too often appear pathologically hostile toward making money. This is perhaps a strange aversion to one of the most honest forms of power - making money by fair exchange, based on one's own talents - at a time when much community art practice has too often become deeply complicit with the less savoury forces of power such as land developers working with local authorities, and arts councils working with government departments to ease through wrong-headed national policies (such as the UK's Housing Pathfinders, among many others) at a local level. The sites of the planned London Olympics, and their surrounding communities, also immediately suggest themselves as a possible case-study for such complicities.

\section{A final caution (2). "Meanwhile, back in the real world":}

It is also vital to remember that there is a desperate need for basic literacy in the British population. Here are very brief details of four reports that bear on my own situation in the West Midlands and the United Kingdom: -

1. A 2005 research report from the Oxford Internet Institute claimed that around one third of British households do not own a personal computer, and just under a third of those questioned in a street poll claimed that they were "complete technophobes". (Kinnes, 2005).

2. A UK study by AppTrigger, titled UK Mobile Services Survey Results, January 2008, claims to have found that $57 \%$ of mobile users do not use their phone for anything more than they did in 2003. (AppTrigger, 2008).

3. OECD data shows that $22 \%$ of Britons are essentially functionally illiterate (Layard, 2001). There is an even higher figure of $24.4 \%$ in the West Midlands (Basic Skills Agency, 1995), with $9 \%$ of the population having chronic difficulties with literacy.

4. There is also a question mark over map-reading literacy, although the evidence is sketchy. An August 2007, a newspaper summary of an independent survey conducted for eSure (based on a sample of 1000 drivers, aged 18 to 65) claimed that...

"Over a third of motorists struggled to read a four-figure [ Ordnance Survey map ] grid reference [...] When tested on their map reading skills, only 1 per cent would pass the Cub Scout Map Reader badge, which is aimed at 6 to 17 year olds." (Map Room, 2006).

Although the latter item appears to be timed as a PR-driven 'silly season' survey, and so should be treated with severe caution, such findings seem to me likely to reflect a general limited level of maprelated skills in the UK population.

Without some basic level of literacy, let alone geospatial literacy, large sections of the population may be shut out from the benefits of neogeography, or will only have to access it very imperfectly via public libraries and friends. In the long term, certain practical applications of neogeography risk further skewing the British housing market and thus job markets. Worse, we may all become subjected to it, if the technology comes to be used for the purpose of repression and the restriction of our liberties.

$\underline{\text { www.d-log.info }}$

6,500 words. $6^{\text {th }}$ July 2008 , England. 


\section{References:}

Abrams, Janet, and Hall, Peter (2006). Else/Where: Mapping - New Cartographies of Networks and Territories. University of Minnesota Design Institute.

http://www.elsewheremapping.com/

AppTrigger. UK Mobile Services Survey Results, January 2008.

http://www.apptrigger.com/downloads/UK_Mobile_Services_Results_20080122.pdf

Basic Skills Agency (1995). Writing Skills Survey by Opinion Research Business.

"Seventeen independent surveys were conducted throughout England. Some 8,804 interviews were completed with adults ranging from 16 to $60 . "$

Brook, James, et al. (1998). Reclaiming San Francisco: history, politics, culture : a city lights anthology. City Lights.

Certeau, Michel de. (1980) "Walking in The City". IN: L'invention du Quotidien. Vol. 1: Arts de Faire. Coverley, Merlin (2006). Psychogeography. Pocket Essentials.

Dagognet, Francois (1977). Une epistemologie de l'espace concret: neo-geographie (Problemes et controverses). Librairie Philosophique J. Vrin.

DeJean, J. E. (1997). Ancients Against Moderns: Culture Wars and the Making of a Fin de Siecle. University of Chicago Press.

Elden, Stuart (2004). Understanding Henri Lefebvre: Theory and the Possible. Continuum Int.

Gill, Martin, and Spriggs, Angela (2005). Home Office Research Study 292: Assessing the impact of CCTV. Home Office Research, Development and Statistics Directorate.

Gregory-Guider, Christopher (2007). “Deep Maps: William Least Heat-Moon's Psychogeographic Cartographies". esharp, issue 4.

Heath, Joseph, and Potter, Andrew (2006). The Rebel Sell: How the Counter Culture Became Consumer Culture. Capstone.

Herring, Charles (1994). "An Architecture of Cyberspace: Spatialization of the Internet". U.S. Army Construction Engineering Research Laboratory.

Toru Ishikawaa, et al (2008). "Wayfinding with a GPS-based mobile navigation system: A comparison with maps and direct experience" . Journal of Environmental Psychology. Volume 28, Issue 1, March 2008, pages 74-82 
Jablonski, Chris (2005). "O'Reilly: Web 2.0 to be built on the backs of hackers". ZDNet online news report, June 29th, 2005.

http://blogs.zdnet.com/BTL/index.php?p=1565

Jackson, Joab (2006). “'Neogeography' Blends Blogs With Online Maps". National Geographic News, $25^{\text {th }}$ April 2006.

http://news.nationalgeographic.com/news/2006/04/0425_060425_map_blogs.html

Kinnes, Sally (2005). “One in three rejects technology”. The Sunday Times, $10^{\text {th }}$ July 2005.

http://technology.timesonline.co.uk/tol/news/tech_and_web/article542214.ece

Layard, R, et al. (2001). "Britain's record on skills". London School of Economics.

http://cep.Ise.ac.uk/layard/britains_skills_record.pdf

Lefebvre, Henri (1974). La Production de l'Espace.

(Has multiple French editions, and multiple English translations.)

Lefebvre, Henri (1995). Writings on Cities. Wiley.

(Edited anthology of his writings on cities)

Map Room, The (2007). “A Third of Britain Can't Read a Map". 6 th $^{\text {th }}$ August 2007.

http://www.mcwetboy.net/maproom/2007/08/a_third_of_brit.php

Miller, Madeleine Sweeny, and Miller, John Lane (1944). Encyclopedia of Bible Life. Harper \& brothers.

Newitz, Annalee (2006). "Where 2.0 Gives the World Meaning". Wired News, $16^{\text {th }}$ June 2006.

http://www.wired.com/science/discoveries/news/2006/06/71170

Nold, Christian (2005). The Greenwich Emotion Map project.

http://www.emotionmap.net/

Price, Michael (2006). "Interview: Platial.Com Co-Founder Di-Ann Eisnor". A weblog posting, posted $11^{\text {th }}$ July 2006 at the weblog "Mike's Corner: Real Estate's New Rules, New Tools".

http://www.mlpodcast.com/blog/archive/2006_07_01_archive.html

Ross, Kristin (1983) (Interviewer and translator). "Henri Lefebvre on the Situationist International". Published in October, 79, Winter 1997.

Shanahan, Andrew (2007). 230 Miles of Love.

http://www.230milesoflove.com/ 
Szott, Randall (2006a) (aka Placekraft / Dilettante Ventures). "Psychogeography vs. Neogeography". A weblog posting, posted on Placekraft on $7^{\text {th }}$ April 2006.

http://placekraft.blogspot.com/2006/04/psychogeography-vs-neogeography.html

Szott, Randall (2006b) (aka Placekraft / Dilettante Ventures). "Neogeography defined". A weblog posting, posted on Placekraft on $26^{\text {th }}$ April 2006.

http://placekraft.blogspot.com/2006/04/neogeography-defined.html

Szott, Randall (2006c) (aka Placekraft). "What is neogeography anyway?" A weblog posting, posted on Placekraft on Platial News and Neogeography: The official weblog of Platial, on $27^{\text {th }}$ May 2006.

http://platial.typepad.com/news/2006/05/what_is_neogeog.html

Turner, Andrew (2006). Introduction to Neogeography (O'Reilly Short Cuts series). O'Reilly Media.

Turner, Andrew (2007). Neogeography - towards a definition. A weblog posting, posted on High Earth Orbit, $6^{\text {th }}$ December 2007.

http://highearthorbit.com/neogeography-towards-a-definition/

Udell, Jon (2005). "Annotating the planet with Google Maps: open, XML-based design makes it a service factory for the geospatial Web". InfoWorld, $4^{\text {th }}$ March 2005.

http://www.infoworld.com/article/05/03/04/100Pstrategic_1.html

Website of the first O'Reilly “Where 2.0" conference. $29^{\text {th }}-30^{\text {th }}$ June 2005, in San Francisco.

http://conferences.oreillynet.com/where2005/

www.neogeography .net (2006). Domain name was registered by Jeffrey Barke on $25^{\text {th }}$ July 2006.

Website visited July 2008.

www.technology.slashgeo.org Slashgeo.

www.platial.com Palatial Inc.

Yearbook of the Carnegie Institution of Washington (1922).

Chronica botanica: an international biological and agricultural series. Vol.14, 1950-54, pages 163-

182. Digitized by the University of California, $19^{\text {th }}$ July 2007 